supportive relatives, and a happy transfer back to the referring hospital might be impeded because of her loss of confidence in it. A further disadvantage of in utero transfer was that much needed beds might be blocked by unnecessary referral, as in Manchester, where only $20 \%$ of antenatally transferred infants needed definitive ventilatory support. ${ }^{4} \mathrm{We}$, however, found that two thirds of our referrals required ventilatory assistance and did not encounter difficulties in accommodating mothers on our postnatal wards. Our subjective experience was that mothers appreciated being near their babies even though they often returned home before their baby was able to be discharged back to the referring hospital.

Patients who were transferred in utero in our study had better Apgar scores at both one and five minutes, and, as skilled resuscitation is so important for low birthweight babies, all high risk deliveries should take place where properly trained personnel and short term respiratory support are constantly available. The combined mortality in our inborn and in utero transfer groups was $15 \%$ compared with $30 \%$ in the rest of the Yorkshire region, thus emphasising the important benefits of the facilities that are available in large neonatal intensive care units.

Any study like this is confounded by the inherent differences among the study groups. The outborn infants transferred to us probably represented the more severely ill patients from the population, and their mortality cannot reasonably be compared with those not transferred. Similarly, the incidence of intraventricular haemorrhage in infants who are not transferred but remain in district general hospitals is unknown, and it is crucial that long term follow up studies are undertaken comparing infants transferred with those treated locally.

Although we have not shown a significant difference in mortality among our three populations, we believe that transfer in utero has definite emotional and psychological advantages that should not be disregarded. Although it is not easy to compare the cost of an in utero transfer with that undertaken by a neonatal flying squad, in utero transfer does have the considerable advantage of not temporarily depleting regional neonatal units, which are invariably understaffed, of both nursing and medical personnel. We believe that paediatric and obstetric staff in district general hospitals, where facilities for intensive care are not immediately available, should liaise with their regional centre to determine the most appropriate action for each woman who presents with preterm labour.

We thank those paediatricians who referred babies to our unit, the nurses and junior doctors for expertly looking after them, and Mrs A Hartup for typing the manuscript.

\section{References}

1 Harris TR, Isaman JI, Giles HR. Improved neonatal survival through maternal transport. Obstet Gynecol 1978;52:294-300.

2 Blake AM, Pollitzer MJ, Reynolds EOR. Referral of mothers and infants for intensive care. $\mathrm{Br}$ Med f 1979;ii:414-6.

3 Cooke RWI. In utero transfer to specialist centres. Arch Dis Child 1983;58:483-4.

4 Chiswick ML. Perinatal referral: a time for decisions. BrMed f 1982;285:83-4.

5 Papile LA, Burstein J, Burstein R, Koffler H. Incidence and evolution of subependymal and intraventricular hemorrhage: a study of infants with birthweights less than $1500 \mathrm{gms}$. I Pediatr 1978;92:529-34.

6 Marascuilo LA, McSweeney M. Non-parametric and distribution free methods for the social sciences. California: Brooks Cole, 1976:410-4.

7 Cordero L, Backes CR, Zuspan FP. Very low birth weight infants-influence of place of birth on survival. Am $\mathcal{O}$ Obstet Gynecol 1982;143:533-7.

8 Blake AM, McIntosh N, Reynolds EOR, St Andrew D. Transport of newborn infants for intensive care. Br Med f 1975; iv: 13-7.

9 Sims DG, Wynn J, Chiswick ML. Outcome for newborn babies declined admission to a regional neonatal intensive care unit. Arch Dis Child 1982;57:334-7.

10 Modanlou HD, Dorchester W, Freeman RK, Rommal C. Perinatal transport to a regional perinatal centre in a metropolitan area: maternal versus neonatal transport. Am $\mathcal{F}$ Obstet Gynecol perinatal centre in a mo; $138: 1157-64$.

11 Lobb ML, Morgan MEI, Bond AP, Cooke RWI. Transfer before delivery on Merseyside: an analysis of the first 140 patients. Br f Obstet Gynaecol 1983;90:338-41.

12 Clark CE, Clyman RI, Roth RS, et al. Risk factors of intraventricular hemorrhage in low-birthweight infants. F Pediatr 1981;99:625-8.

\title{
Effects of nutrient intake, surgery, sepsis, and long term administration of steroids on muscle function
}

\author{
W BROUGH, G HORNE, A BLOUNT, M H IRVING, K N JEEJEEBHOY
}

\begin{abstract}
The stimulated contraction-relaxation characteristics of the adductor pollicis muscle were used to assess nutritional state in patients and healthy controls. In both groups insufficient nutrition resulted in abnormal muscle function. The ratio of force of contraction at $10 \mathrm{~Hz}$ to that at $20 \mathrm{~Hz}$ yielded the best combination of sensitivity (87\%) and specificity (82\%). Sepsis resulted in abnormal muscle function, but the changes were easily distinguishable from those in subjects taking an inadequate diet. Long term administration of steroids, trauma, and surgery
\end{abstract}

\footnotetext{
Department of Surgery, Hope Hospital (University of Manchester School of Medicine), Salford M6 8HD

W BROUGH, BSC, FRCS, lecturer in surgery

G HORNE, BSC, research technician

A BLOUNT, SRD, dietitian

M H IRVING, MD, FRCS, professor of surgery

K N JEEJEEBHOY, MD, Medical Research Council, visiting professor

Correspondence to: Professor Irving.
}

had no effect on muscle function. A prospective study of 11 malnourished patients with abnormal muscle function showed that all variables of muscle function returned to normal values with total parenteral nutrition. This reversal correlated significantly with the duration of parenteral nutrition and occurred before any change in anthropometric variables or plasma albumin concentration.

Muscle function studies are sensitive and specific indicators of malnutrition; results depend on energy intake but are not influenced by administration of steroids, trauma, or surgery.

\section{Introduction}

Insufficient dietary intake results in malnutrition with wasting of muscle and alteration in the composition of the body. ${ }^{1}$ Traditional assessments of malnutrition are based on anthropometry, hepatic protein synthesis, delayed cutaneous hypersensitivity, total body nitrogen content, and creatinine-height index. ${ }^{23}$ Changes in these objective measurements may be associated with non-nutritional factors such as malignancy, sepsis, and immobility ${ }^{5}$ and are no better than subjective clinical assessment in predicting complications of disease associated with nutrition. ${ }^{6}$ It has always been 
assumed that a large mass of tissue protein (that is, muscle, albumin) in relation to height protects patients from the adverse effects of malnutrition. In previous studies, however, we showed that obese subjects with a supranormal body nitrogen content develop muscle fatigue and atrophy of type II muscle fibres together with $Z$ band degeneration when given a $1673 \mathrm{~kJ}$ (400 kcal) diet for two weeks. These changes occur even when the body fat, potassium, and nitrogen contents of the subjects exceed the expected mean values for their height. Further studies in patients with anorexia nervosa and in rats have shown that the most important factor altering muscle function is insufficient nutrient intake in relation to requirement. ${ }^{8}$

The aim of the present study was to determine: (1) whether muscle function is a sensitive and specific measure of a diet insufficient for metabolic requirements; (2) whether sepsis, trauma, long term administration of steroids, and operation alter muscle function; and (3) whether abnormal muscle function is reversed by nutritional support. intake on the three to four days before repeat studies of muscle function. Patients were classified as eucaloric and eating a balanced diet when energy intake was equal to, or greater than, the measured or estimated metabolic rate one week before assessment of muscle function. Control subjects and patients voluntarily dieting or with an energy intake of less than $90 \%$ of their resting metabolic rate were classified as hypocaloric.

\section{MUSCLE FUNCTION TESTING}

The functional tests of the adductor pollicis muscle were performed by Edwards's modification of Merton's method. ${ }^{10} 11$ Before the study the hand was warmed by immersion in water at $40-50^{\circ} \mathrm{C}$ for 10 minutes. The technique entailed linking a strain gauge by a chain to a loop around the interphalangeal joint of the right thumb. The hand was secured palm upwards with the fingers flexed and the thumb abducted, its metacarpointerphalangeal joint fully extended to give a maximal twitch response. The muscle was tested at a constant isometric length.

The ulnar nerve was supramaximally stimulated at the wrist with a square wave impulse of $80-100 \mathrm{~V}$ lasting $50-100 \mu$ s. The force of the adductor

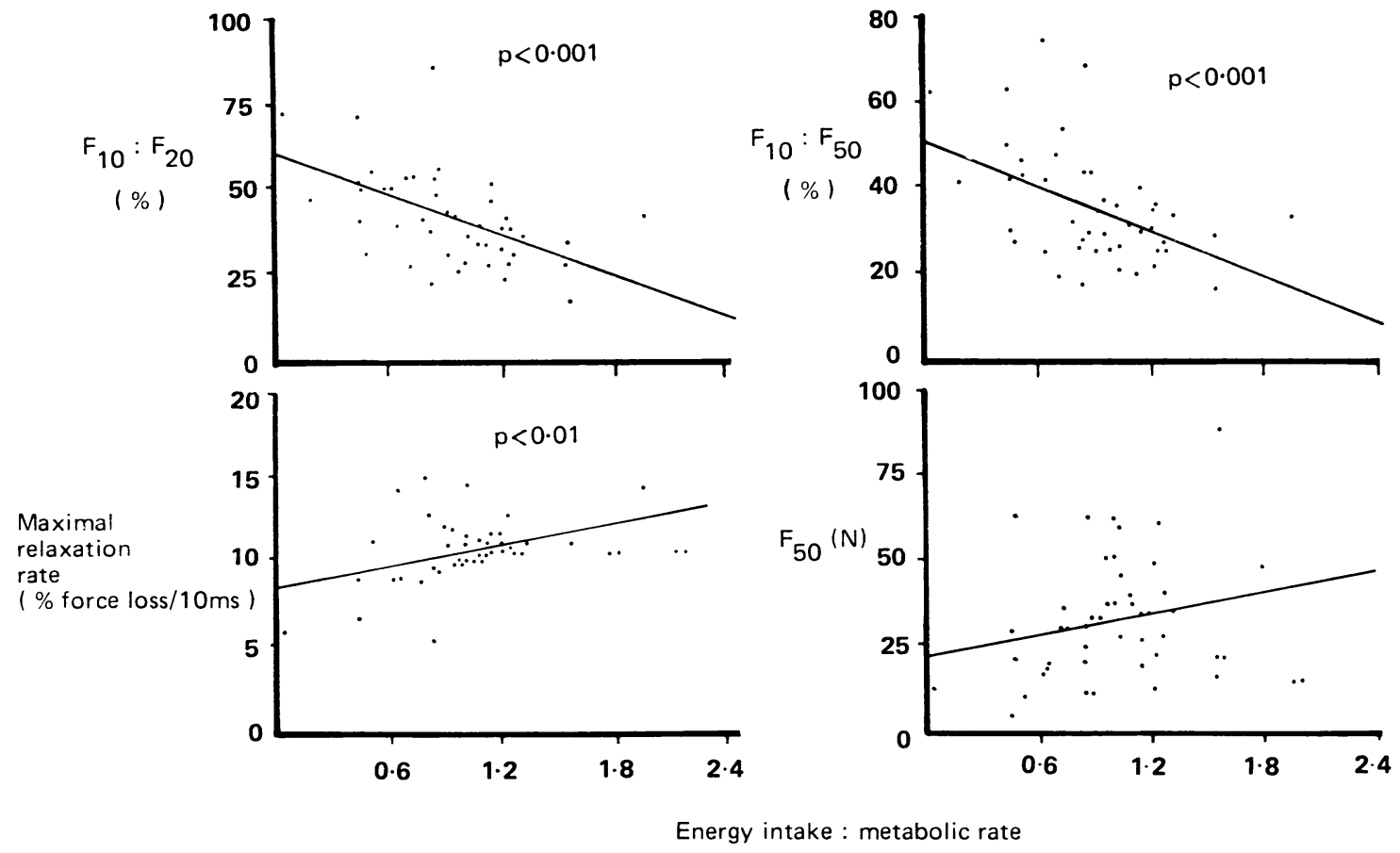

FIG 1-Correlation of variables of muscle function with ratio of energy intake to metabolic rate.

TABLE I-Correlation of variables of muscle function with age in eucaloric subjects

\begin{tabular}{lcc}
\hline & Significance & $\mathrm{R}^{2}$ \\
\hline $\mathrm{F}_{10}: \mathrm{F}_{20}$ & $\mathrm{p}<0 \cdot 001$ & $0 \cdot 10$ \\
$\mathrm{~F}_{10}: \mathrm{F}_{50}$ & $\mathrm{p}<0 \cdot 001$ & $0 \cdot 09$ \\
$\mathrm{~F}_{50}$ & NS & $0 \cdot 02$ \\
Maximal relaxation rate & NS & $0 \cdot 02$ \\
\hline
\end{tabular}

\section{Subjects and methods}

\section{EFFECT OF ENERGY INTAKE ON MUSCLE FUNCTION}

Control subjects and patients were divided into those who consumed a balanced diet sufficient for their resting metabolic rate and those eating less than $90 \%$ of the amount sufficient for their resting metabolic rate. Before their muscle function was tested all subjects were interviewed by a dietitian, using the Microdiet computer program, to assess protein and energy intake in the weeks leading up to admission. ${ }^{9}$ Subsequent interviews assessed pollicis was recorded with a calibrated transducer on a strip chart and recorder. Electromyograms were recorded using a surface electrode over the adductor pollicis muscle and reference electrodes on the tips of the second and third fingers, ensuring constant nerve stimulation throughout the study.

The ulnar nerve was stimulated at 10,20 , and $50 \mathrm{~Hz}$, the force of contraction being recorded at each frequency of stimulation. The procedure

TABLE II-Effect of energy intake on variables of muscle function. Values are mean (SEM)

\begin{tabular}{|c|c|c|c|c|}
\hline & $\begin{array}{l}\text { Eucaloric } \\
\text { controls } \\
(\mathrm{n}=39)\end{array}$ & $\begin{array}{l}\text { Hypocaloric } \\
\text { controls } \\
(\mathrm{n}=11)\end{array}$ & $\begin{array}{c}\text { Eucaloric } \\
\text { patients } \\
(\mathrm{n}=74)\end{array}$ & $\begin{array}{l}\text { Hypocaloric } \\
\text { patients } \\
(\mathrm{n}=12)\end{array}$ \\
\hline $\begin{array}{l}\mathrm{F}_{10}: \mathrm{F}_{20}(\%) \\
\mathrm{F}_{10}: \mathrm{F}_{50}(\%)\end{array}$ & $\begin{array}{l}34 \cdot 6(1 \cdot 3) \\
28 \cdot 3(1 \cdot 0)\end{array}$ & $\begin{array}{l}41 \cdot 3(3 \cdot 3)^{\star} \\
33 \cdot 1(3 \cdot 5)\end{array}$ & $\begin{array}{l}45 \cdot 0(1 \cdot 6)^{\star \star \star} \\
35 \cdot 2(1 \cdot 3)^{\star \star \star}\end{array}$ & $\begin{array}{l}59 \cdot 0(5 \cdot 0) \\
49 \cdot 1(4 \cdot 4)\end{array}$ \\
\hline $\begin{array}{c}\text { Maximal relaxation } \\
\text { rate }(\% \text { maximal } \\
\text { force loss } / 10 \mathrm{~ms})\end{array}$ & $11 \cdot 5(0 \cdot 2)$ & $10 \cdot 9(0.5)$ & $11 \cdot 5(0.3)$ & $8.9(0.6)^{\star}$ \\
\hline$F_{s_{0}}(\mathbf{N})$ & $37 \cdot 7(2 \cdot 8)$ & $33 \cdot 8(4 \cdot 9)$ & $26 \cdot 7(1 \cdot 5)^{\star \star \star}$ & $20 \cdot 7(3 \cdot 9)^{\star \star \star}$ \\
\hline
\end{tabular}

Compared with the eucaloric controls: ${ }^{\star} \mathrm{p}<0.02 ;{ }^{\star \star} \mathrm{p}<0.005 ;{ }^{\star \star \star} \mathrm{p}<0.001$. 
was repeated on two occasions with a high degree of reproducibility. ${ }^{12}$ The effect of post-tetanic potentiation was standardised by using a fixed order of testing. Results were averaged to obtain the forces for the various frequencies of stimulation. To compare the results of these studies in people with differing degrees of muscularity we expressed the force of contraction at $10 \mathrm{~Hz}$ as a percentage of the maximal force obtained with electrical stimulation at $20 \mathrm{~Hz}\left(\mathrm{~F}_{10}: \mathrm{F}_{20}\right)$ and at $50 \mathrm{~Hz}\left(\mathrm{~F}_{10}: \mathrm{F}_{50}\right)$. In addition the maximal force of contraction at $50 \mathrm{~Hz}$ was noted $\left(\mathrm{F}_{50}\right)$.

The maximal relaxation rate of the adductor pollicis muscle was determined in the unfatigued state after a brief tetanic stimulation $(2-3 \mathrm{~s})$ at $20 \mathrm{~Hz}$. The rate was calculated from the steepest part of the slope of relaxation and expressed as a percentage of the maximal force loss $/ 10 \mathrm{~ms}$.

values. Although patients were studied for different periods of time, the relation between the reversal of muscle function and the duration of total parenteral nutrition was determined.

\section{Results}

\section{EFFECT OF AGE}

There was a significant but weak correlation of age with the ratios of the force of contraction $\left(\mathrm{F}_{10}: \mathrm{F}_{20}\right.$ and $\mathrm{F}_{10}: \mathrm{F}_{50} ;$ table $\left.\mathrm{I}\right)$ but none between age and the maximal relaxation rate or the maximal force of contraction $\left(\mathrm{F}_{50}\right)$.
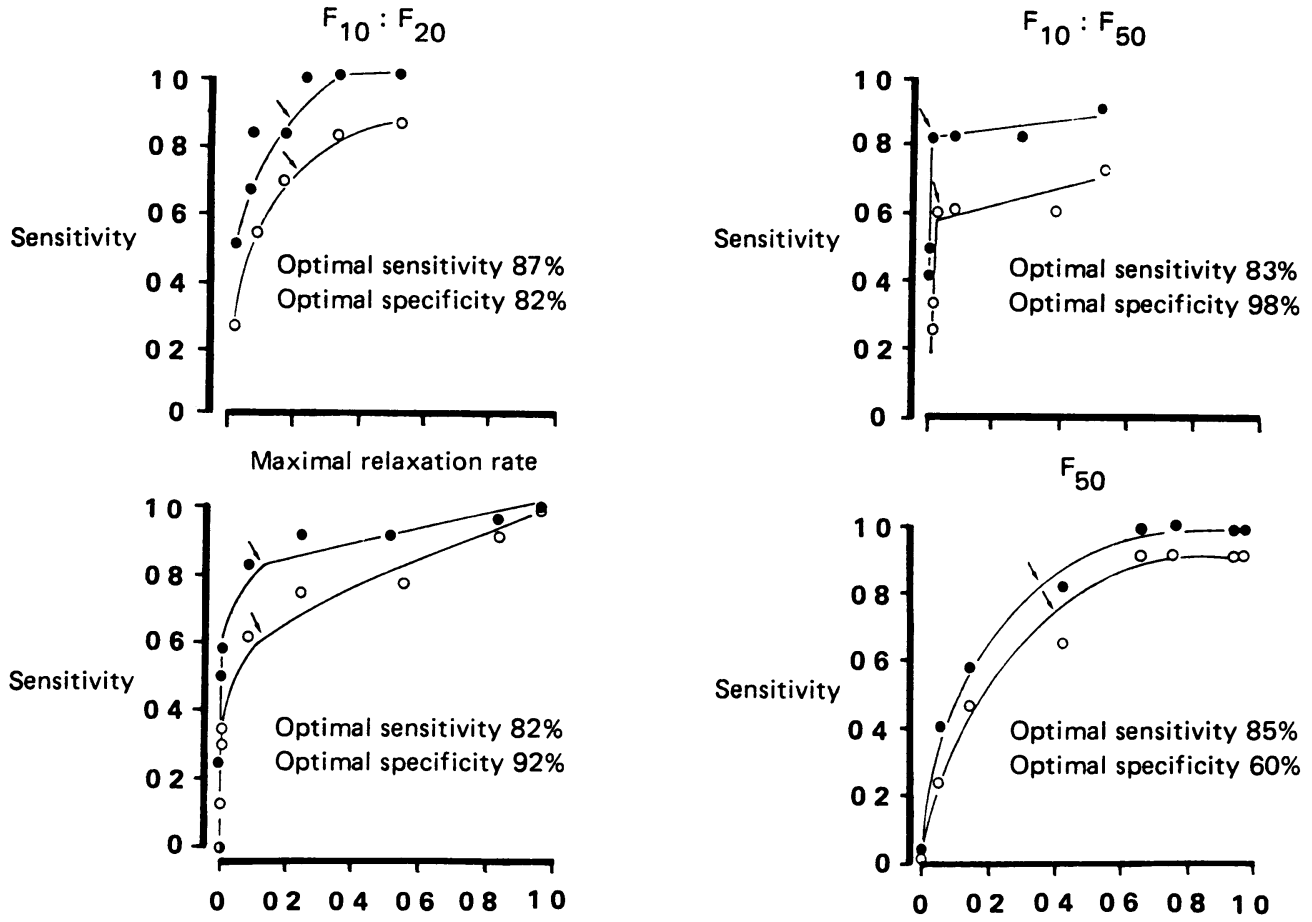

False positive rate ( 1 -specificity )

FIG 2-Receiver-operator characteristic curves for variables of muscle function: sensitivity of each variable plotted against false positive rate ( 1 - specificity). Arrows indicate optimal sensitivity. $\bullet-\bullet=$ All subjects except hypocaloric controls. $\bigcirc-O=$ All subjects.

\section{STATISTICAL ANALYSIS}

Analysis of results was by Student's $t$ test for unpaired and paired data. All values in the test and tables are presented as means (SEM).

\section{SUBJECTS STUDIED}

Muscle function studies were performed in 39 healthy eucaloric controls (17 men, 22 women); 11 healthy hypocaloric controls who were voluntarily on a diet; 74 eucaloric patients ( 32 men, 42 women); and 12 hypocaloric patients. Of the 74 eucaloric patients, 63 were admitted in a eucaloric state and 11 became eucaloric after admission as a result of enforced feeding in hospital.

The effect on muscle function of long term administration of steroids, acute trauma, elective surgery, and sepsis was determined in eucaloric patients. Seven patients without infection taking $30 \mathrm{mg}$ prednisolone a day orally were studied for the effect of long term steroids. Four acutely injured eucaloric patients with multiple fractures but not requiring operation were studied on admission to hospital; muscle function studies were performed more frequently in this group to assess any early changes. The effect of surgery on muscle function was assessed in the recovery room in six patients immediately after elective laparotomy for intra-abdominal procedures. Further studies were carried out in 15 well nourished eucaloric patients with intra-abdominal sepsis and a sepsis score greater than $5 .^{13}$

Finally, the effect of controlled refeeding on muscle function was studied in 11 hypocaloric patients before and during total parenteral nutrition. The end point of the study was reached when muscle function returned to normal

\section{EFFECT OF GENDER IN EUCALORIC CONTROLS}

In the eucaloric control group (17 men, 22 women) there was no significant difference between men and women in the ratios of the force of contraction or the maximal relaxation rate. As expected, however, the men had a significantly greater maximal force of contraction at $50 \mathrm{~Hz}$ than the women $(p<0 \cdot 05)$.

\section{CONTROL GROUPS}

A significant difference was observed between the eucaloric and hypoclaoric control groups in the ratio of force of contraction $F_{10}: F_{20}(p<0.025)$ but not in the ratio $F_{10}: F_{50}$. There was no significant difference in the maximal relaxation rate or maximal force of contraction despite a significant reduction in nutrient intake. The hypocaloric control group differed most from the eucaloric patients in the maximal force of contraction $(p<0.05)$.

\section{PATIENT GROUPS}

A significant difference was observed between the 74 eucaloric patients and the 12 hypocaloric patients in the ratios of force of contraction, maximal relaxation rate, and maximal force of contraction compared with the eucaloric controls (table II). A comparison between the eucaloric controls and the eucaloric patients showed a significant difference in the ratios of force of contraction and the maximal force of contraction but not in the maximal relaxation rate. When patient and control groups were combined 
the ratio of energy intake to metabolic rate showed a significant correlation with the measurements of muscle function except the maximal force of contraction (fig 1).

\section{EFFECTS OF STEROIDS, SURGERY, AND TRAUMA}

The seven eucaloric patients receiving long term treatment with steroids and the six studied after laparotomy did not show any significant difference from the eucaloric control group in any of the variables of muscle function (table III). The four eucaloric patients studied after admission for acute trauma showed a transient reduction in the maximal relaxation rate $(\mathrm{p}<0.05)$, but this variable returned to normal within 72 hours of admission; the remaining variables did not show any significant difference from those in the control group.

\section{EFFECT OF SEPSIS}

The 15 eucaloric patients with sepsis had increased ratios of force of contraction compared with the eucaloric controls (table IV). These higher ratios were significantly lower, however, than those in the hypocaloric patients. Furthermore, the patients with sepsis had a relaxation rate that was not significantly different from that in the eucaloric controls or eucaloric patients but was significantly faster than that in the hypocaloric patients $(\mathrm{p}<0.02)$.

In contrast, the maximal force of contraction in the patients with sepsis was significantly lower than that in the eucaloric controls but did not differ from that in the eucaloric or hypocaloric patients. This suggests that sepsis exerts a small effect on the ratio of force of contraction and the maximal force of contraction compared with the effects of insufficient nutrient intake.

\section{SENSITIVITY AND SPECIFICITY OF MUSCLE FUNCTION TESTS IN DETERMINING INADEQUATE ENERGY INTAKE}

To define the optimal cut off point for dividing subjects into "test positive" and "test negative" groups we constructed "receiver-operator characteristic curves." "In brief, this entailed determining the proportion of patients who had an "abnormal" (test positive) variable of muscle function who were hypocaloric (disease positive). These patients were compared with those who had an abnormal variable but were disease negative (eucaloric), to give the false positive rate. The value of an abnormal test was varied over the range of observations and the partition of patients into true and false positives plotted as a graph. As the criteria for an abnormal test are widened the proportion of patients who are recognised as being true positives (test positive and disease positive) rises. If the test is a good one, however, the false positive rate does not rise as much, if at all. These receiver-operator characteristic curves were plotted for each variable of muscle function (fig 2).

The tests of muscle function discriminated well because the sensitivity (true positive rate) rose steeply with a minimal increase in the false positive rate. When the sensitivity reached approximately $0.85(85 \%)$ a further increase in the criteria for abnormality resulted in an increase in the false positive rate; this was the point at which conditions for discrimination were optimal. The cut off point to distinguish between disease negative and disease positive patients for the ratio of force of contraction $F_{10}: F_{20}$ was taken as $42 \%$, with an optimal sensitivity of $87 \%$ and optimal specificity of $82 \%$. Similarly, the ratio $\mathrm{F}_{10}: \mathrm{F}_{50}$, with a cut off point at $36 \%$, had a sensitivity of $83 \%$ and specificity of $98 \%$. The maximal relaxation rate was cut off at $10 \%$ of the maximal force loss $/ 10 \mathrm{~ms}$, resulting in an optimal sensitivity of $82 \%$ and specificity of $92 \%$. In contrast, the maximal force of contraction, with a cut off point at $30 \mathrm{~N}$, had an optimal sensitivity of $85 \%$ but a decreased specificity of $60 \%$. These calculated cut off values allowed the tests of muscle function described to discriminate between eucaloric and hypocaloric patients.

EFFECT OF TOTAL PARENTERAL NUTRITION ON MUSCLE FUNCTION, ANTHROPOMETRIC VARIABLES, AND SERUM ALBUMIN CONCENTRATION

Eleven patients were studied before and at weekly intervals during controlled total parenteral nutrition. All patients were receiving this for severe malnutrition, alone or associated with sepsis. The effect of refeeding on muscle function, anthropometric variables, and serum albumin concentration was compared. Before refeeding, the malnourished patients had significantly abnormal variables of muscle function (table V). After refeeding there was a significant reduction in the ratio of the force of contraction and a significant increase in the maximal relaxation rate.
TABLE III-Effect of steroids, surgery, and trauma on muscle function. Values are means (SEM)

\begin{tabular}{lcccc}
\hline & $\begin{array}{c}\text { Eucaloric } \\
\text { controls } \\
(\mathrm{n}=39)\end{array}$ & $\begin{array}{c}\text { Patients } \\
\text { after trauma } \\
(\mathrm{n}=4)\end{array}$ & $\begin{array}{c}\text { Patients } \\
\text { given steroids } \\
(\mathrm{n}=7)\end{array}$ & $\begin{array}{c}\text { Patients } \\
\text { after surgery } \\
(\mathrm{n}=6)\end{array}$ \\
\hline $\mathrm{F}_{10}: \mathrm{F}_{20}(\%)$ & $34 \cdot 6(1 \cdot 3)$ & $42 \cdot 7(5 \cdot 9)$ & $33 \cdot 1(2 \cdot 0)$ & $37 \cdot 5(2 \cdot 8)$ \\
$\begin{array}{l}\mathrm{F}_{10}: \mathrm{F}_{50}(\%) \\
\begin{array}{l}\text { Maximal relaxation } \\
\text { rate }(\% \text { maximal } \\
\text { force loss } / 10 \mathrm{~ms})\end{array}\end{array}$ & $28 \cdot 3(1 \cdot 0)$ & $34 \cdot 8(4 \cdot 7)$ & $25 \cdot 1(1 \cdot 9)$ & $30 \cdot 0 \cdot 0 \cdot 9$ \\
$\mathrm{~F}_{50}(\mathrm{~N})$ & $11 \cdot 5(0 \cdot 2)$ & $9 \cdot 6(1 \cdot 0)$ & $11 \cdot 9(0 \cdot 7)$ & $11 \cdot 5(0 \cdot 6)$ \\
\hline
\end{tabular}

TABLE IV-Effect of sepsis on muscle function. Values are means (SEM)

\begin{tabular}{llccc}
\hline & $\begin{array}{c}\text { Eucaloric } \\
\text { controls } \\
(\mathrm{n}=39)\end{array}$ & $\begin{array}{c}\text { Eucaloric } \\
\text { patients with } \\
\text { sepsis } \\
(\mathrm{n}=15)\end{array}$ & $\begin{array}{c}\text { Hypocaloric } \\
\text { patients } \\
(\mathrm{n}=12)\end{array}$ & $\begin{array}{c}\text { Eucaloric } \\
\text { patients } \\
(\mathrm{n}=74)\end{array}$ \\
\hline $\mathrm{F}_{10}: \mathrm{F}_{20}(\%)$ & $34 \cdot 6(1 \cdot 3)^{\star}$ & $40 \cdot 7(3 \cdot 3)$ & $59 \cdot 0(5 \cdot 0)^{\star \star \star}$ & $45 \cdot 0(1 \cdot 6)$ \\
$\mathrm{F}_{10}: \mathrm{F}_{50}(\%)$ & $28 \cdot 3(1 \cdot 0)^{\star \star \star}$ & $33 \cdot 1(2 \cdot 5)$ & $49 \cdot 1(4 \cdot 4)^{\star \star \star}$ & $35 \cdot 2(1 \cdot 3)$ \\
$\begin{array}{l}\text { Maximal relaxation } \\
\text { rate }(\% \text { maximal } \\
\text { force loss } / 10 \mathrm{~ms})\end{array}$ & $11 \cdot 5(0 \cdot 2)$ & $11 \cdot 6(0 \cdot 9)$ & $8 \cdot 9(0.6)$ & $11 \cdot 5(0 \cdot 3)$ \\
$\mathrm{F}_{50}(\mathrm{~N})$ & $37 \cdot 7(2 \cdot 8)^{\star}$ & $26 \cdot 6(3 \cdot 8)$ & $20 \cdot 7(3 \cdot 0)$ & $26 \cdot 7(1 \cdot 5)$ \\
\hline
\end{tabular}

Compared with the patients with sepsis: ${ }^{\star} \mathrm{p}<0.05 ;{ }^{\star \star} \mathrm{p}<0.002 ;{ }^{\star \star \star} \mathrm{p}<0.005$

TABLE V-Effect of total parenteral nutrition on variables of muscle function. Values are means (SEM)

\begin{tabular}{lccc}
\hline & $\begin{array}{c}\text { Eucaloric } \\
\text { controls } \\
(\mathrm{n}=39)\end{array}$ & $\begin{array}{c}\text { Before } \\
\text { refeeding } \\
(\mathrm{n}=11)\end{array}$ & $\begin{array}{c}\text { After } \\
\text { refeeding } \\
(\mathrm{n}=11)\end{array}$ \\
\hline $\mathrm{F}_{10}: \mathrm{F}_{20}(\%)$ & $34 \cdot 6(1 \cdot 3) \star \star$ & $58 \cdot 0(3 \cdot 7)$ & $40 \cdot 1(2 \cdot 1)^{\star \star}$ \\
$\mathrm{F}_{10} \mathrm{~F}_{50}(\%)$ & $28 \cdot 3(1 \cdot 0)^{\star \star \star}$ & $48 \cdot 4(5 \cdot 1)$ & $33 \cdot 6(2 \cdot 1)$ \\
$\begin{array}{l}\text { Maximal relaxation } \\
\quad \text { rate }(\% \text { maximal }\end{array}$ & $11 \cdot 5(0 \cdot 2)^{\star \star \star}$ & & \\
$\quad$ force loss/10 ms $)$ & $37 \cdot 7(2 \cdot 8)^{\star \star \star}$ & $20 \cdot 3(0 \cdot 4)$ & $12 \cdot 3(0 \cdot 5) \star \star \star$ \\
$\mathrm{F}_{50}(\mathrm{~N})$ & & $30 \cdot 5(2 \cdot 8)^{\star}$ \\
\hline
\end{tabular}

Compared with values before refeeding: ${ }^{\star} \mathrm{p}<0.025 ;{ }^{\star \star} \mathrm{p}<0 \cdot 005 ;{ }^{\star \star \star} \mathrm{p}<0.001$.

TABLE VI-Effect of total parenteral nutrition on arm muscle circumference, triceps skinfold thickness, and serum albumin concentration. Values are means (SEM)

\begin{tabular}{lccc} 
& $\begin{array}{c}\text { Eucaloric } \\
\text { controls } \\
(\mathrm{n}=39)\end{array}$ & $\begin{array}{c}\text { Before } \\
\text { refeeding } \\
(\mathrm{n}=11)\end{array}$ & $\begin{array}{c}\text { After } \\
\text { refeeding } \\
(\mathrm{n}=11)\end{array}$ \\
\hline Arm muscle circumference $(\mathrm{cm})$ & $33 \cdot 2(1 \cdot 8)$ & $21 \cdot 3(1 \cdot 9)$ & $20 \cdot 1(2 \cdot 2)$ \\
Triceps skinfold thickness $(\mathrm{mm})$ & $14 \cdot 1(1 \cdot 9)$ & $\begin{array}{r}9 \cdot 3(1 \cdot 2) \\
28 \cdot 4(1 \cdot 7)\end{array}$ & $\begin{array}{r}10 \cdot 3(1 \cdot 0) \\
28 \cdot 9(1 \cdot 8)\end{array}$ \\
Albumin $(\mathrm{g} /)^{\star}$ & & &
\end{tabular}

$\star^{\star}$ Normal range $35-45 \mathrm{~g} / 1$

Similarly, a $50 \%$ increase in the maximal force of contraction $(p<0.025)$ was seen during refeeding.

There were no significant changes in the mid-arm muscle circumference, triceps skinfold thickness, or serum albumin concentration during the study period (table VI).

Effect of duration of total parenteral nutrition-A significant correlation was seen between the reversal of all abnormal results of muscle function studies and the duration of total parenteral nutrition (fig 3 ).

\section{Discussion}

Muscle function as determined by the ratio of the force of contraction $\left(\mathrm{F}_{10}: \mathrm{F}_{20}\right.$ or $\left.\mathrm{F}_{10}: \mathrm{F}_{50}\right)$ and maximal relaxation rate were independent of gender and only weakly dependent on age. The maximal force of contraction $\left(F_{50}\right)$ was dependent on gender, which made standardisation difficult. Hence the effects of nutrient intake on the ratios of force of contraction and maximal relaxation rate could be compared in groups with different age and sex distributions. 
The dominant finding, irrespective of disease, was of a highly significant increase in the ratio of force of contraction in the hypocaloric patients compared with the eucaloric controls and eucaloric patients. Furthermore, the ratios of force of contraction correlated inversely with nutrient intake in relation to metabolic requirements. There was a significant difference in $\mathrm{F}_{10}: \mathrm{F}_{2 \cdot \text { ?. }}$, but not $F_{10}: F_{50}$, between the eucaloric controls and the hypocaloric controls, who were on a self imposed diet. The hypocaloric controls, however, did not differ from the 74 eucaloric patients, 11 of whom were at varying stages of refeeding after previous nutrient deprivation. Thus at the time of the muscle function studies the eucaloric patients may not have been receiving nutrients for long enough to group and the patients with sepsis. Sepsis did not significantly affect the maximal relaxation rate or maximal force of contraction. Hence sepsis seems to influence muscle function in a way that was detected by a small change in the ratio of the force of contraction.

Finally, to confirm the relation between the variables of muscle function and the nutrient intake we showed that in individual patients controlled refeeding by total parenteral nutrition reversed abnormalities of muscle function. Our results confirm that early changes in muscle function occur before changes that are detected by standard methods of nutritional assessment and are easily reversed by refeeding.

In all such studies the question arises of the effect on function of
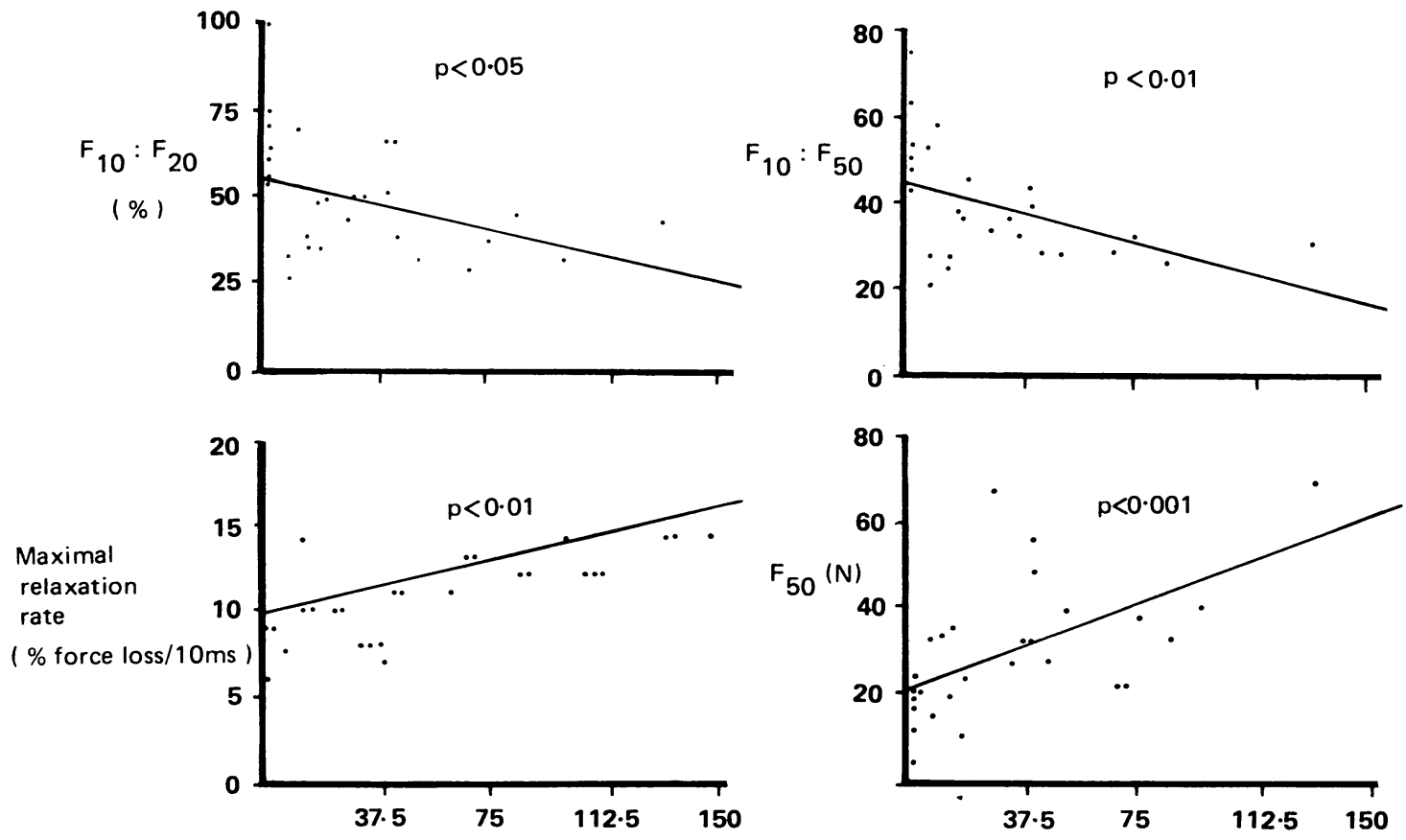

Duration of total parenteral nutrition (days)

FIG 3-Effect of duration of total parenteral nutrition on variables of muscle function.

restore their tests to the control level. This emphasises that in selecting a control group for such studies a careful dietary history must be obtained to exclude people who are dieting.

There was a positive correlation between the maximal relaxation rate and the ratio of nutrient intake to metabolic requirements. The maximal force of contraction was also related to nutrient intake. Decreased nutrient intake resulted in significant alteration in the variables of muscle function. This correlated directly with the ratio of nutrient intake to metabolic requirement - that is, the degree of nutrient deprivation.

Use of steroids and the effect of surgical intervention are unlikely to be confusing factors in the study of nutritional support: provided food intake was normal in relation to metabolic rate these factors had no effect on the variables of muscle function. Trauma was characterised by a transient slowing of the maximal relaxation rate but no change in the force-frequency response. Hence a consistent change in both force-frequency response and maximal relaxation rate cannot be ascribed to injury.

The main abnormality of muscle function in patients with sepsis was in the ratio of the force of contraction. All patients studied were eucaloric but severely ill with sepsis as defined clinically by the sepsis score ${ }^{13}$ Sepsis resulted in an increase in the ratio of force of contraction, but this increased value was much lower than that seen in the hypocaloric patients, who remained an easily distinguishable group, with an abnormally raised ratio of the force of contraction that was significantly different from the value in both the control use and disuse of the muscle, but it is unlikely that disuse can explain the changes. The hypocaloric controls were active nurses and hospital staff; two of those with abnormal muscle function were known to exercise regularly. The general consensus from previous reports is that no major changes in the contractile characteristics of muscle occur in response to varying types of physical training or inactivity. ${ }^{\text {is }}$ Finally, the adductor pollicis muscle of the dominant hand is regularly used in daily activity.

Our study clearly shows that eating a diet containing less than the metabolic requirements will alter muscle function, irrespective of non-nutritional factors of disease. As the major cause of death from malnutrition seems to be failure of respiratory muscle function, and it has been shown by Moxham et al that the adductor pollicis muscle behaves in a similar fashion to that of the diaphragm and sternomastoid muscle, ${ }^{16}$ it is clear that these abnormalities are functionally important. Muscle function, vital for normal existence. seems to be sensitive to reductions in nutrient intake before any change in muscle mass occurs. Further studies to determine the precise nutrients required to prevent or treat abnormal muscle function in malnourished, critically sick patients would be of great importance. In all such patients the effect of use and disuse of the muscle on its function may have a role.

We are grateful to the North Western Regional Health Authority, the Medical Research Council, and the Sheila Dawber Fund for supporting this project. 


\section{References}

1 University of Minnesota Laboratory of Physiology Hygiene. The biology of starvation. Vol 1. Minneapolis: University of Minnesota Press, 1950.

2 Blackburn GL, Bistrian BP, Maini BS, Schlamm HT, Smith MF. Nutritional and metabolic assessment of the hospitalised patient. IPEN 1977;1:11-22.

3 Busby GP, Mullen JL, Mathews DC, Hobbs CL, Rosato FF. Prognostic nutritional index in gastrointestinal surgery. Am $\mathcal{F}$ Surg 1980;139:160-7.

4 Bozetri F, Pagnoni AM, Del Vecchio $M$. Excessive caloric expenditure as a cause of malnutrition in patients with cancer. Surg Gynecol Obstet 1980;150:229-34.

5 Shonheyder F, Heilskor NCS, Oleson K. Isotopic studies on the mechanism of negative nitrogen balance produced by immobilization. Scand J Clin Lab Invest 1954;6:178-88.

6 Balcer JP, Detsky AS, Wesson DE, et al. Nutritional assessment: a comparison of clinical judgement and objective measurements. N Engl f Med 1982;306:969-72.

7 Russell DMcR, Walker PM, Lecter MD, et al. Metabolic and structural changes in skeletal muscle during hypocaloric dieting. Am f Clin Nutr 1984;39:503-13.

8 Russell DMcR, Predergast PJ, Darby PL, et al. A comparison between muscle function and body composition in anorexia nervosa: the effect of refeeding. Am $\mathcal{f}$ Clin Nutr 1983;38:229-37.
9 Bassham S. Microdiet computer program. Journal of Microcomputer Applications 1984;7:1279-89. 10 Edwards RHT, Young A, Hosking GP, Jones DA. Human skeletal muscle function: description of tests and normal values. Clinical Science and Molecular Medicine 1977;52:283-90.

11 Merton PA. Voluntary strength and fatigue. $\mathcal{F}$ Physiol 1954;123:553-64. 11 Merton PA. Voluntary strength and fatigue. F Physiol 1954;123:553-64.
12 Lopes J, Russell DMcR, Whitwell J, Jeejeebhoy KN. Skeletal muscle function in malnutrition.
Am f Clin Nutr 1982:36:602-10

3 Elebute EA, Stoner HB. The grading of sepsis. Br 7 Surg 1983;70:29-31.

14 Debue EA, Stoner HB. The gradng of sepsis. Brf Surg $1983 ; 0: 29-31$. Detsky AS, Baker accuracy of nutritional assessment. Techniques applied to hospital patients. $\mathscr{F} P E N$ 1984;8: $\mathrm{C}$
$153-9$.

15 Saltin B, Gollnick PD. Skeletal muscle. In: Teacher LD, ed. Handbook of Physiology 19. @ Baltimore: American Physiology Society/Waverly, 1983:555-63.

16 Moxham J, Moms AJR, Spiro SG, Edwards RHT, Green M. Contractile properties and fatigue of the diaphragm in man. Thorax $1981 ; 36: 164-8$.

(Accepted 11 fuly 1986)

\title{
Course of blood pressure in mild hypertensives after withdrawal of ${ }_{\hat{\sigma}}^{\vec{\omega}}$ long term antihypertensive treatment
}

\author{
MEDICAL RESEARCH COUNCIL WORKING PARTY ON MILD HYPERTENSION
}

\begin{abstract}
A series of 1418 men and 1347 women with mild hypertension (diastolic phase V 90-109 mm Hg) aged 35-64 who had either had long term antihypertensive treatment with bendrofluazide or propranolol or taken placebo tablets for a similar period were randomly allocated to groups in which their tablets were either stopped or continued. The course of blood pressure and of biochemical variables was followed up for two years. Mean blood pressures rose rapidly after the withdrawal of active treatment, and between nine months and one year after stopping treatment the antihypertensive effect had almost disappeared. The effect persisting longer than this, and possibly due to resetting of the baroreceptors or of other blood pressure control mechanisms, was very small, and as the rise in mean pressure was due to an upward movement in general distribution there was no evidence of a subgroup in whom these mechanisms had been permanently reset to a clinically important extent. After withdrawal of propranolol the rise in pressure was more rapid in younger than in older people. After stopping bendrofluazide pressure rose more rapidly in men who had had higher pressures before and during treatment; this effect was not seen in women. Disturbances in biochemical variables associated with drug treatment had largely resolved by the end of two years after withdrawal. Stopping placebo tablets made no consistent difference to blood pressure.
\end{abstract}

\section{Introduction}

Early workers ${ }^{12}$ put forward the hypothesis that the carotid sinus "barostat" mechanism, having been reset at a higher level during periods of hypertension, might again be reset, at a lower level, if the blood pressure could consistently be reduced. If the baroreceptors

\footnotetext{
Members of the working party were: Professor Sir Stanley Peart (chairman), Mrs G R Barnes (until 1983), Mr P M G Broughton, Professor C T Dollery, Dr K G Green (until 1983), Dr M F Hudson, Dr A F Lever, Dr T W Meade, Dr W E Miall (secretary until 1983), Professor G A Rose, and Dr G Greenberg (secretary).
}

Correspondence to: Dr G Greenberg, Epidemiology and Medical Care Unit, Northwick Park Hospital, Harrow, Middlesex HA1 3UJ. were to be reset during a period of successful antihypertensive $\vec{\oplus}$ treatment it should then be possible to discontinue or at least interrupt medication in some hypertensive patients.

The Medical Research Council's trial of treatment of mild $\stackrel{0}{\circ}$ hypertension has provided an opportunity to assess the effect of $\frac{\mathbb{\Phi}}{-}$ withdrawal of long term antihypertensive treatment on the sub- $\vec{\bullet}$ sequent course of blood pressure. Results obtained during screen- $\infty$ ing for that trial suggested that at least one million middle aged people in Britain could be classified as mildly hypertensive with $O$ phase $\mathrm{V}$ diastolic pressures in the range $90-109 \mathrm{~mm} \mathrm{Hg}$. The trial showed that antihypertensive treatment was associated with a $45 \%$ reduction in stroke rate and that $\beta$ blockers possibly reduced the $\frac{\partial}{\nabla}$ rate of coronary events in non-smokers. Antihypertensive treatment $\cong$ at present is often life long, and if it could be shown that treatment $\overrightarrow{\overrightarrow{0}}$ leads to resetting of baroreceptors or other blood pressure control 3 mechanisms at a lower level this would be a major long term benefit; interrupted rather than continuous treatment might then be? possible for some patients, with careful checks on compliance when medication had to be restarted. Interrupted treatment might also identify people in whom pressure remained low for other reasons 0 and in whom further treatment was unnecessary.

\section{Patients and methods}

All patients had taken part in the MRC trial of treatment of mild o hypertension. ${ }^{3}$ Participants in this study were men or women, aged 35-64 at $\frac{D}{2}$ entry, with phase $\mathrm{V}$ diastolic pressure sustained in the range $90-109 \mathrm{~mm} \mathrm{Hg}$. over a screening period lasting several weeks. At entry to the trial $N$ participants were randomly allocated to take either bendrofluazide (fixed N dose, usually $10 \mathrm{mg}$ daily, but $5 \mathrm{mg}$ daily in a small group taking part in a $\mathrm{\omega}$ dose-response substudy), propranolol (80-240 mg daily), or a placebo. The target was a diastolic pressure below $90 \mathrm{~mm} \mathrm{Hg}$, and dose changes of propranolol or supplementary treatment (usually with methyldopa), or $\$$ both, were used as necessary to reach this level. In the few patients in whom? phase $\mathrm{V}$ diastolic pressure could not be recorded phase IV was used instead. 7

Recruitment of the 17354 participants was protracted, and 4286 early entrants had completed their five and a half year follow up (phase I) in $\bigcirc$ advance of the end of the entire study. This gave the opportunity to rerandomise treatment for these people, either to withdrawal or to continuation of their existing regimens. Rerandomisation (for those giving informed consent) took place at the sixth anniversary of entry to phase 1 . The part of $\delta$ the study from then onwards was known as phase 2 .

Of the 4286 people, $1056(24 \cdot 6 \%)$ were ineligible for phase $2: 541(12 \cdot 6 \%)$ were no longer taking trial drugs; $79(1 \cdot 8 \%)$ had had a stroke or a myocardial 